\author{
Nicolas de Prost \\ Georges Saumon \\ Didier Dreyfuss
}

\section{Modeling the time-course of ventilator-induced lung injury: what can we learn from interspecies discrepancies?}

Received: 16 August 2011

Accepted: 22 August 2011

Published online: 4 November 2011

(C) Copyright jointly held by Springer and ESICM 2011

This editorial refers to the article available at: doi:10.1007/s00134-011-2388-9.

N. de Prost $(\bowtie)$

Service de Réanimation Médicale, Hôpital Henri Mondor, Assistance Publique-Hôpitaux de Paris,

51, Avenue Du Maréchal de Lattre de Tassigny,

94010 Créteil Cedex, France

e-mail: nicolas.de-prost@hmn.aphp.fr

Tel.: +33-1-49812391

Fax: +33-1-49812542

\section{G. Saumon · D. Dreyfuss}

Université Paris-Diderot and PRES Sorbonne Paris Cité, Site Xavier Bichat, 75018 Paris, France

D. Dreyfuss

Service de Réanimation Médicale, Hôpital Louis Mourier, Assistance Publique-Hôpitaux de Paris, 92700 Colombes, France

D. Dreyfuss

INSERM U722, 75018 Paris, France

Alterations in lung fluid balance, increases in endothelial and epithelial permeability, and severe tissue damage have been widely described in animals following injurious mechanical ventilation and regrouped under the term ventilator-induced lung injury (VILI) [1]. The clinical relevance of VILI was highlighted by the acute respiratory distress syndrome (ARDS) Network trial that showed a $22 \%$ reduction of mortality in patients with ARDS when the mechanical stress applied to the lungs was lessened by reducing the tidal volume applied [2]. The pathophysiology of VILI is unequivocal, and several mechanical determinants of VILI have been identified to date: (1) regional overdistension caused by the application of a local stress or pressure that forces cells and tissues to assume shapes and dimensions that they do not assume during unassisted breathing [3-5]; (2) so-called "low volume injury" associated with the cyclic recruitment-derecruitment of lung units [6], which causes abrasion of the epithelial airspace lining by interfacial forces [7]; (3) inactivation of surfactant triggered by large alveolar surface area oscillations [8]; (4) the interdependence mechanism that raises cell and tissue stress between neighboring structures with differing mechanical properties [9]. Early experimental studies demonstrated that the main determinant of VILI is lung end-inspiratory volume, associated with high transpulmonary pressures $[10,11]$. Thus, the term "volutrauma" is preferred to the term "barotrauma", since the absolute level of airway pressure per se is not injurious [10].

The severity of VILI depends both on the degree (as determined by ventilator settings) and duration of the mechanical insult applied to the lungs and on the sensitivity of the lungs to VILI, which differs according to animal species. For example, Webb and Tierney demonstrated that rats subjected to mechanical ventilation using peak inspiratory pressures of 30 or $45 \mathrm{cmH}_{2} \mathrm{O}$ developed pulmonary edema within 60 and $20 \mathrm{~min}$, respectively, following its onset [3], and Dreyfuss et al. showed that pulmonary edema occurred after only $5 \mathrm{~min}$ of injurious mechanical ventilation in healthy rats [5]. In contrast, in larger animal species, longer ventilation periods and higher peak inspiratory pressures are required for the development of VILI: lambs mechanically ventilated at $58 \mathrm{cmH}_{2} \mathrm{O}$ peak inspiratory pressures for $6 \mathrm{~h}$ only developed mild pulmonary edema [12], and the average time required for the development of impairment in gas exchanges and pulmonary mechanics in sheep ventilated with $50 \mathrm{cmH}_{2} \mathrm{O}$ peak inspiratory pressures was $24 \mathrm{~h}$ [13]. 
Clearly, the ventilation time needed to produce severe edema is less than $1 \mathrm{~h}$ in small species but in the 24-h range in large animals.

Gatinoni and colleagues have recently introduced new conceptual insights into the study of VILI mechanisms by considering the different effects of strain [i.e., the ratio between volume change (tidal volume plus positive endexpiratory pressure volume) and lung resting volume] and stress (i.e., the transpulmonary pressure) on the expanding lung $[14,15]$. Performing computed tomography (CT) imaging on patients with ARDS, they demonstrated that neither the plateau pressure nor the tidal volume applied were adequate surrogates for lung stress and strain due to the large variability of both the functional residual capacity and the chest wall mechanics-i.e., the position of the tidal volume varied along the pressure-volume curve of the respiratory system [14]. In an article appearing in the current issue of Intensive Care Medicine, Caironi et al. report the results of a meta-analysis aimed at testing their hypothesis that only the extent of the maximal stress and strain applied to healthy lungs can account for the timecourse of the development of VILI among different species [16]. These authors retrospectively selected and reviewed 20 articles, including those on five mammal species, which report data on healthy animals ventilated until the achievement of a pre-terminal lung injury. The main finding of their meta-analysis was that the time of achievement of a pre-terminal VILI was inversely and exponentially correlated with the lung strain applied $\left(r^{2}=0.85\right)$, as well as with the lung strain weighted for the inspiratory/expiratory time $\left(r^{2}=0.83\right)$. This finding provides a unifying rule describing the time-course of VILI in mammals with healthy lungs. Interestingly enough, when the lung strain rose above a threshold value of 2 (e.g., as would be obtained after inflating $5 \mathrm{~L}$ of gas into the lungs of a $70-\mathrm{kg}$ healthy male human being having a functional residual capacity of approximately $2.5 \mathrm{~L}$ ), the time to achieve VILI dropped down to few minutes; in contrast, below this threshold value, the time-course of VILI was much slower. This result suggests that the contribution of mechanisms other than lung strain to the development of VILI, such as those occurring at low lung volume, is relatively more important. The lung strain threshold reported by these authors is consistent with the existence of an airway pressure threshold above which dramatic increases in lung microvascular permeability occur $[4,17]$. When the lung strain applied was accounted for, the time to achieve VILI was greater in larger animals than in smaller ones, implying that the former are more resistant to VILI than the latter. Lungspecific compliance (i.e., lung compliance normalized by lung resting volume) is identical from "bats to whales" [18] and can thus hardly be considered as an important factor determining the different sensitivities of mammal species to VILI. As discussed by Caironi et al., the greater sensitivity of small animals to VILI can be partially explained by a lower functional residual capacity relative to body weight and by a lower contribution of chest wall to respiratory system elastance, both leading to a greater strain than that which occurs in larger animals following the application of a similar transpulmonary pressure [16]. That the mammal species in their meta-analysis exhibited different lung deformation in response to the application of an equivalent stress likely explains the finding that, as opposed to lung strain, lung stress was poorly associated with the timecourse of VILI $\left(r^{2}=0.25\right)$.

The study by Caironi et al. [16] certainly has several limitations related to its retrospective nature: (1) the formula used for the computation of strain relied on the assumption of a mono-alveolar lung model and thus did not account for lung heterogeneity and the possibility of alveolar recruitment during inflation; (2) functional residual capacity and partitioned lung mechanics were not actually measured but derived from previously published morphometric data in healthy animals; (3) the lack of assessment of other mechanisms/determinants of VILI than stress and strain, i.e., mainly cyclic recruitmentderecruitment and regional stress and strain heterogeneities. It must also be emphasized that the exponential relationship linking the time to achieve VILI with lung strain only holds true in a specific experimental setting, i.e., VILI developing in normal lungs, and has not been tested in animals with pre-injured lungs $[19,20]$. This relationship can thus not be extrapolated to humans with diseased lungs. In fact, the same group has recently demonstrated that the amount of lung cyclically opening and closing, but not lung stress and strain, is associated with mortality in ARDS patients [21].

Regardless of these limitations, the article by Caironi et al. [16] will further our understanding of the interspecies differences that characterize the time-course of experimental VILI developing in healthy lungs. As such, it provides key information that will improve our understanding of the discrepancies between the experimental studies that led to the very concept of VILI. As a matter of fact, current aspects of the management of ARDS patients, such as tidal volume reduction, were derived from these seminal studies involving both small and large mammals and even applied to patients before the publication of the ARDS Network study [2, 22]. Of course, the contribution of lung strain to the time-course of VILI must not obviate that of other potential contributors to VILI, such as cyclic recruitment-derecruitment, when mechanical ventilation is applied on previously diseased lungs [21, 23]. Finally, the clinical relevance and the extent to which strain is deleterious are to be confirmed since a meta-analysis in ARDS patients revealed that the application of higher versus lower positive end-expiratory pressure levels, with the associated increase in lung strain, led to a reduction in mortality [24]. Further studies are thus warranted to assess whether this unifying relationship could be applied to earlier endpoints than preterminal VILI and to previously injured lungs. 


\section{References}

1. Dreyfuss D, Saumon G (1998)

Ventilator-induced lung injury: lessons from experimental studies (State of the Art). Am J Respir Crit Care Med 157:1-30

2. The Acute Respiratory Distress Syndrome Network (2000) Ventilation with lower tidal volumes as compared with traditional tidal volumes for acute lung injury and the acute respiratory distress syndrome [see comments]. N Engl J Med 342 (18):1301-1308

3. Webb HH, Tierney DF (1974)

Experimental pulmonary edema due to intermittent positive pressure ventilation with high inflation pressures. Protection by positive end-expiratory pressure. Am Rev Respir Dis 110:556-565

4. Parker JC, Townsley MI, Rippe B, Taylor AE, Thigpen J (1984) Increased microvascular permeability in dog lungs due to high airway pressures. J Appl Physiol 57:1809-1816

5. Dreyfuss D, Basset G, Soler P, Saumon G (1985) Intermittent positive-pressure hyperventilation with high inflation pressures produces pulmonary microvascular injury in rats. Am Rev Respir Dis 132:880-884

6. Muscedere JG, Mullen JBM, Gan K, Bryan AC, Slutsky AS (1994) Tidal ventilation at low airway pressures can augment lung injury. Am J Respir Crit Care Med 149:1327-1334

7. Bilek AM, Dee KC, Gaver DP 3rd (2003) Mechanisms of surface-tensioninduced epithelial cell damage in a model of pulmonary airway reopening. J Appl Physiol 94:770-783

8. Faridy EE, Permutt S, Riley RL (1966) Effect of ventilation on surface forces in excised dogs' lungs. J Appl Physiol 21:1453-1462

9. Mead J, Takishima T, Leith D (1970) Stress distribution in lungs: a model of pulmonary elasticity. J Appl Physiol 28:596-608
10. Dreyfuss D, Soler P, Basset G, Saumon G (1988) High inflation pressure pulmonary edema. Respective effects of high airway pressure, high tidal volume, and positive end-expiratory pressure. Am Rev Respir Dis 137:1159-1164

11. Hernandez LA, Peevy KJ, Moise AA, Parker JC (1989) Chest wall restriction limits high airway pressure-induced lung injury in young rabbits. J Appl Physiol 66:2364-2368

12. Carlton DP, Cummings JJ, Scheerer RG, Poulain FR, Bland RD (1990) Lung overexpansion increases pulmonary microvascular protein permeability in young lambs. J Appl Physiol 69:577-583

13. Kolobow T, Moretti MP, Fumagalli R, Mascheroni D, Prato P, Chen V, Joris M (1987) Severe impairment in lung function induced by high peak airway pressure during mechanical ventilation. Am Rev Respir Dis 135:312-315

14. Chiumello D, Carlesso E, Cadringher P, Caironi P, Valenza F, Polli F, Tallarini F, Cozzi P, Cressoni M, Colombo A, Marini JJ, Gattinoni L (2008) Lung stress and strain during mechanical ventilation for acute respiratory distress syndrome. Am J Respir Crit Care Med 178(4):346-355

15. Gattinoni L, Protti A, Caironi P, Carlesso E (2010) Ventilator-induced lung injury: the anatomical and physiological framework. Crit Care Med 38:S539-S548

16. Caironi P, Langer T, Carlesso E, Protti A, Gattinoni L (2011) Time to generate ventilator-induced lung injury among mammals with healthy lungs: a unifying hypothesis. Intensive Care Med. doi: 10.1007/s00134-011-2388-9

17. de Prost N, Dreyfuss D, Saumon G (2007) Evaluation of two-way protein fluxes across the alveolo-capillary membrane by scintigraphy in rats: effect of lung inflation. J Appl Physiol 102:794-802
18. Taylor AE, Rehder K, Hyatt RE, Parker JC (1989) Mechanics of breathing: static. In: Wonsiewicz M (ed) Clinical respiratory physiology. Saunders, Philadelphia, p 93

19. Dreyfuss D, Martin-Lefevre L, Saumon G (1999) Hyperinflation-induced lung injury during alveolar flooding in rats: effect of perfluorocarbon instillation.

Am J Respir Crit Care Med 159:1752-1757

20. Dreyfuss D, Soler P, Saumon G (1995) Mechanical ventilation-induced pulmonary edema. Interactions with previous lung alterations. Am J Respir Crit Care Med 151:1568-1575

21. Caironi P, Cressoni M, Chiumello D, Ranieri M, Quintel M, Russo SG, Cornejo R, Bugedo G, Carlesso E, Russo R, Caspani L, Gattinoni L (2010) Lung opening and closing during ventilation of acute respiratory distress syndrome. Am J Respir Crit Care Med 181:578-586

22. Jardin F, Farcot JC, Boisante L, Curien N, Margairaz A, Bourdarias JP (1981) Influence of positive end-expiratory pressure on left ventricular performance. N Engl J Med 304:387-392

23. de Prost N, Costa EL, Wellman T, Musch G, Winkler T, Tucci MR, Harris RS, Venegas JG, Vidal Melo MF (2011) Effects of surfactant depletion on regional pulmonary metabolic activity during mechanical ventilation. J Appl Physiol (Epub 28 July 2011)

24. Briel M, Meade M, Mercat A, Brower RG, Talmor D, Walter SD, Slutsky AS, Pullenayegum E, Zhou Q, Cook D, Brochard L, Richard JC, Lamontagne F, Bhatnagar N, Stewart TE, Guyatt G (2010) Higher vs lower positive endexpiratory pressure in patients with acute lung injury and acute respiratory distress syndrome: systematic review and meta-analysis. JAMA 303:865-873 